\title{
LUT
}

University

\section{Enhancing situational awareness on fragmented information in complex systems with workflow information network analysis}

Metso Lasse, Marttonen-Arola Salla, Linnimaa Samu, Kinnunen Sini-Kaisu, Kärri
Timo

This is a Author's accepted manuscript (AAM) version of a publication published by Inderscience Publishers

in International Journal of Industrial and Systems Engineering

DOI: $\quad 10.1504 /$ IJISE.2020.112069

Copyright of the original publication: (c) 2021 Inderscience Enterprises Ltd.

Please cite the publication as follows:

Metso, L., Marttonen-Arola, S., Linnimaa, S., Kinnunen, S.-K., Kärri, T. (2020). Enhancing situational awareness on fragmented information in complex systems with workflow information network analysis. International Journal of Industrial and Systems Engineering, Vol. 36 No. 4, pp.577-590. DOI: 10.1504/IJISE.2020.112069

This is a parallel published version of an original publication. This version can differ from the original published article. 


\title{
Enhancing Situational Awareness on Fragmented Information in Complex Systems with Workflow Information Network Analysis
}

\author{
Lasse Metso*, Salla Marttonen-Arola, Samu \\ Linnimaa, Sini-Kaisu Kinnunen and Timo Kärri
}

Industrial Engineering and Management,

LUT University

P.O. Box 20

53851 Lappeenranta, FINLAND

Email: lasse.metso@lut.fi

Email: Salla.Marttonen-Arola@ sunderland.ac.uk

Email: samu.linnimaa@pp.inet.fi

Email: sini-kaisu.kinnunen@lut.fi

Email: timo.karri@lut.fi

*Corresponding author

\begin{abstract}
In industrial contexts, information is usually fragmented into a complex network of organizations and systems. To develop their information management, the organizations need to obtain and maintain situational awareness of their workflows, and identify and understand relevant information and how the planned actions affect the system in the near future. This paper introduces Workflow Information Network Analysis, a managerial method for analysing and improving situational awareness in complex systems. The method is built on the principles of information management, product lifecycle management and value network analysis. A six-step process for applying the method is presented, and the validity of the method has been demonstrated with a case study in which the information flows of a networked aircraft maintenance organisation are analysed. The case study shows that the method enables the identification of discontinuities and bottlenecks in information flows, as well as produces suggestions for further development.
\end{abstract}

Keywords: situational awareness, Workflow Information Network Analysis; WINA, information flows, case study, aviation, aircraft maintenance, complex system, fragmented information

Reference to this paper should be made as follows: Metso, L., MarttonenArola, S., Linnimaa, S., Kinnunen, S-K. and Kärri, T. (2019) 'Enhancing Situational Awareness on Fragmented Information in Complex Systems with Workflow Information Network Analysis Title', Int. J. Industrial and Systems Engineering,

\section{Biographical notes:}

Lasse Metso is a Post-doctoral Researcher at the School of Engineering Science in the department of Industrial Engineering and Management, LUT 
University (Lappeenranta-Lahti University of Technology), Finland. He received his D.Sc. (Tech.) in 2013. After his Master's degree in Industrial Engineering and Management from LUT University in 2000, he worked at a software company and, since 2007, at the university as a lecturer and researcher. His main research interests are asset management, especially information management in industrial maintenance and maintenance ecosystems.

Salla Marttonen-Arola is a Research Fellow within the Faculty of Technology at the University of Sunderland (UK), and an Adjunct Professor in value and profitability of industrial asset management at LUT University (Finland). She received her D.Sc. (Tech.) in 2013 and after that she has worked as a researcher and project manager on several national and international research projects in Finland and in the UK. These projects have been conducted in collaboration with academic and industrial partners from e.g. mining, energy and engineering industries. Her research interests include the costs and value of industrial asset management, specifically in the context of industrial ecosystems.

Samu Linnimaa (MSc) is a Manager of process \& competence Development in an international airline. He received his Master's degree in Industrial Engineering and Management from LUT University in 2016.

Sini-Kaisu Kinnunen (MSc) is a PhD student at the School of Engineering Science in the department of Industrial Engineering and Management, LUT University. She received her Master's degree in Industrial Engineering and Management from LUT University in 2014. She currently works in the research team of Capital, Capacity and Cost Management (C3M). Her main research interests are cost management, value and profitability of asset management, and especially the value of fleet data in asset management.

Timo Kärri is a Professor at the School of Engineering Science in the department of Industrial Engineering and Management, LUT University. He received his D.Sc. (Tech.) in Industrial Engineering and Management, and the dissertation considered the timing of capacity changes in capital intensive industries. Kärri's current research topics include industrial asset management, capital investments and working capital management, and he has specialized in life-cycle costing and cost modelling. With his research group C3M, he has written over a 100 scientific publications. Kärri has wide teaching experience in the above mentioned areas and he has also acted as responsible manager in many industrial research projects.

\section{Introduction}

In today's competitive business landscape, companies tend to focus on their core competencies and network with other organizations providing e.g. various support services during the lifecycle of the core product (e.g. Caglio \& Ditillo, 2012; Meira et al., 2010; Shalij et al., 2009). In practice this has led to the emergence of complex interorganizational systems around the products. Effective communication between 
organizations and inter-organizational IT system integration are often still lacking, resulting in fragmented product information in the business networks (e.g. Candell et al., 2009; Ranasinghe et al., 2011). Technical solutions for inter-organizational information sharing exist (see e.g. Ferreirab et al., 2017; Olaisen \& Revang, 2017), but collaborative practices and attitudes supporting information sharing are often lacking. In addition, confirming the quality of the information is important to ensure valid conclusions (Citroen, 2011). Information failures can lead to disasters such as the Fukushima nuclear power accident (see Thacher et al., 2015). The poor quality of data makes collaboration between service providers and suppliers difficult (Siponen et al. 2019). Decision-makers have difficulties gathering the multifaceted information from several sources at the right time and in the right form. In these complex inter-organizational systems, it is difficult for any of the organizations operating around the product to obtain and maintain the situational awareness required for optimal workflow information management.

Situational awareness is a term mostly used in military contexts and in aviation (see e.g. Endsley, 1988 and 1995), but which has also been introduced to information management (see e.g. Tesone \& Goodall, 2007). Situational awareness means identifying and understanding the relevant information about what is happening in the system with regards to the set objectives, and also how the planned actions affect the system in the near future. Situational awareness can be maintained through effective communications regarding e.g. the goals of the system or network as a whole, the individual tasks of the network actors, and the roles and responsibilities of the actors. (US Department of Homeland Security, 2004) Situational awareness improves the effectiveness of decisionmaking in complex and dynamic environments (Harrald \& Jefferson, 2007). The term awareness is used widely, e.g. for environmental purposes in developing lighter aircraft parts to minimize pollution (Veeramanikandan et al. 2019).

In this paper, we introduce a novel managerial method for 1) analysing the current state of situational awareness on fragmented information in complex systems, and 2) identifying development needs to improve the information flows from the perspective of enhancing situational awareness. The main purpose of the presented method is to support organizations in developing practices and tools for their information management. We call this method Workflow Information Network Analysis (WINA). The existing managerial tools, such as value network analysis and product lifecycle management, provide valuable perspectives and principles for achieving situational awareness, but only result in partial awareness. We use these existing bodies of knowledge to formulate a new managerial construct specifically focused on managing workflow information in complex systems. The paper also presents a case study from the aviation industry to further demonstrate the use and benefits of WINA in complex industrial data management contexts.

The structure of the paper is as follows. In section 2, previous literature is presented, and in section 3, WINA is introduced as a management support tool such as product lifecycle management and value network analysis. Section 4 presents research design and the case study, and the paper finishes with conclusions in section 5.

\section{Literature review}

The following paragraphs provide a brief introduction into a number of bodies of knowledge (information management, product lifecycle management, and value network 
analysis) from the specific perspectives required in forming situational awareness on fragmented information. Despite having extensively contributed to enhancing the operations of modern companies and business networks, these existing methods individually do not provide systematic and concrete tools for optimally analysing the current status and future needs of information flows needed to support operational workflows. Thus we suggest combining features from these methods into a novel managerial concept.

Business in general can be seen based on gathering, interpreting, and exploiting various information (see e.g. Pareschi \& Fontana, 2016). However, the amount of information available for decision-makers is already extensive, and the rapid increase in the amount of sensors, use of cloud-based computing, as well as interconnected assets and systems (e.g. the Internet of Things) are providing yet more data (Baglee et al., 2015). Thus the amount of information is overwhelming, and most of the collected data is never even used in decision-making (Kinnunen et al., 2016). Situational awareness is easily disturbed if there is too much data (Davenport \& Prusac, 2000; Karim et al., 2009; Meissen et al., 2005). Davenport and Prusac (2000) as well as Symon (2000) state that specific rules for information management should be established to keep the information flows in control. Lack of rules and clarity can disturb the workflow of an organization (Stark, 2015). Of course, human resources should have been taken into consideration while planning and scheduling actions, and responsibilities must be clear as well (Calais et al., 2017). Many engineering systems are interconnected to humans, and humans play a key role in the availability of systems (Karimi et al., 2018).

Product lifecycle management (PLM) is an information-driven concept guiding an organization's processes, staff, practices, and technology to trade the information from the whole lifecycle of a product across the company and its supply chain (see e.g. Grieves, 2008). Often there are disruptions in the product information flows when the product has been handed over to the end customer (Hong-Bae \& Kiritsis, 2012). When successful, PLM enhances information transparency from one phase of the product lifecycle to another through system integration and defined information flows. The usual goals are to improve the quality of the product, or to enhance the support services and functions of the product. (Christian, 2015, see also Stark, 2015; Takata et al., 2004) PLM was first implemented in contexts requiring exceptional safety and control, for instance the medical industry, nuclear energy, and aviation (PLM, 2015). Numerous PLM software have been introduced for industrial use, but in practice their interconnectivity with other information systems continues to limit their usage (see e.g. Camba et al., 2017; Soto-Acosta et al., 2016).

Companies tend to operate in business networks (see e.g. Caglio \& Ditillo, 2012; Meira et al., 2010), and most large companies are organized according to functions, creating several sources and users for the information. Thus common understanding of the information flows, software, platforms etc. is required before each department or organization in the network can use the information according to their own needs. (Karim et al., 2009; Silventoinen et al., 2014; Stark, 2015) An additional challenge is created by the diversity of inter-organizational relationships and accordingly varying requirement levels for communication and collaboration present in the networks (Barlow \& Li, 2005). Business networks can be seen as sets of value interactions and roles within and between organizations striving for an agreed objective. Value network analysis (VNA) and organizational network analysis (ONA) are tools used to analyse and improve an organization's capability to realize value for itself and for other network members out of 
various tangible and intangible assets. (Allee, 2008; Merrill et al., 2007) VNA can be seen to adopt rather a multi-layered perspective to the network, since it is typical to analyse the flows of tangible goods, services, revenue, and information in the network to reach a comprehensive understanding of value creation. Accordingly, the emergence of service-dominant logic in value creation literature presents value as a complex phenomenon created jointly in inter-organizational interaction (see. e.g. La Rocca \& Snehota, 2014; Vargo \& Lusch, 2008).

To achieve situational awareness, a workflow or process view should be taken to integrate the necessary features of PLM, information management and VNA. This will provide organizations with means to manage and optimize their information from a lifecycle perspective while operating in complex networks. Process management can be seen as a set of activities for planning and monitoring the performance of business processes (Becker et al., 2011). Process management tools, techniques, visualization, measurements and control reports are used to define business processes (Thom, 2009). Process management is adopted here because it can offer tools to develop, implement and improve the quality of systems (Van Houten, 2000; Moumen and Aoufir, 2018), for example with a value stream mapping (VSM) technique which can be used to optimize resources (Samant et al. 2018) and simulation for optimizing maintenance phases (Huang et al. 2018).

\section{Workflow information network analysis}

In this section, we introduce WINA, a novel managerial method for analysing and improving organizations' situational awareness on fragmented information in complex systems. WINA is derived from several existing methods and bodies of knowledge, including product lifecycle management, some aspects of information management, and value network analysis.

PLM forms the foundation for WINA, but it is supported by principles characteristic to VNA. Applying just VNA to the fragmented information landscapes would be challenging because of the multi-layered scope of the method. WINA pursues concrete information management improvements by focusing solely on the analyses of information flows, whereas VNA focuses on the analyses of material and monetary flows. There is no question about the need for evaluating processes in order to gain more efficiency with the limited resources in companies (Paryzad et al. 2018). Tsarouhas (2019) has evaluated the reliability, availability and maintainability of a production line based on failure data analysis. For information supply between several actors, existing literature identifies four distinct aspects that must be managed (see Davenport \& Prusac, 2000; Karim et al., 2009; Meissen et al., 2005): 1) time; when to deliver information, 2) content; what information to deliver, 3) communication; how to deliver information, and 4) context; where and why to deliver information. While VNA adopts a rather strategic birds-eye view and focuses mostly on content and context, WINA also takes the time and communication aspects into account. Through the time dimension, the main ideas of PLM can also be integrated into the analysis. Figure 1 summarizes the dimensions addressed by WINA. 


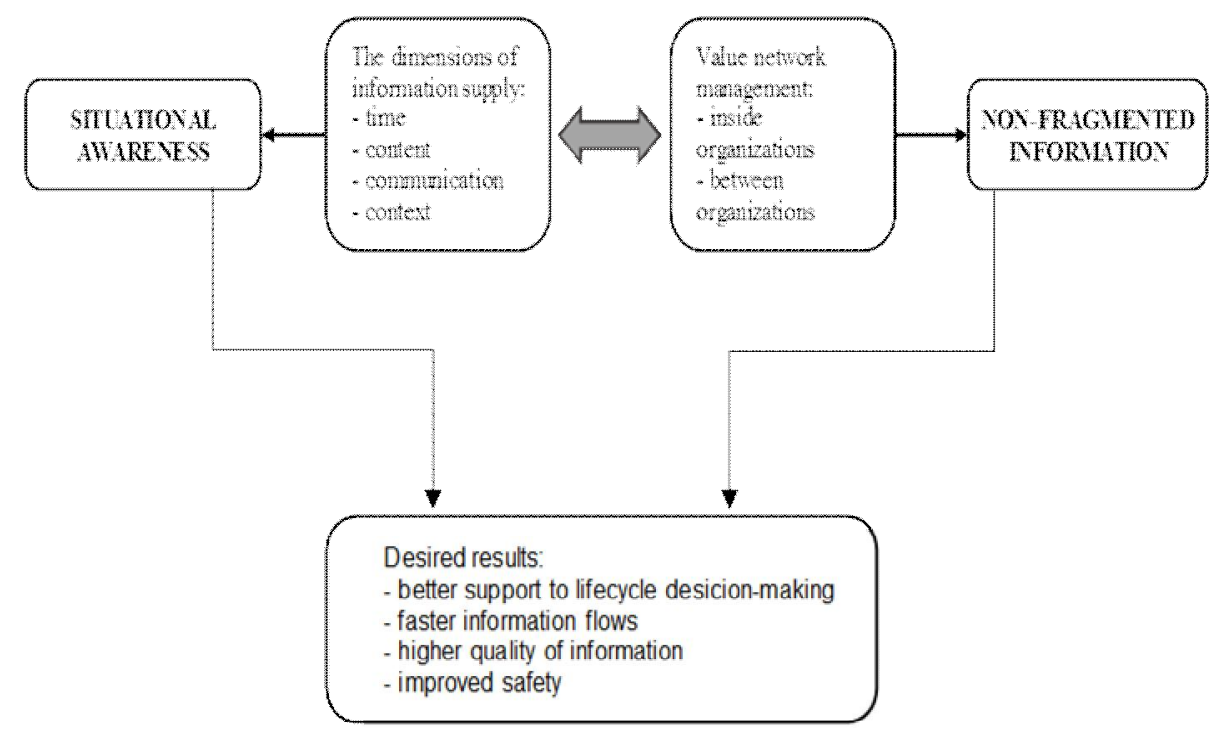

Figure 1. The dimensions of WINA.

WINA provides a visual way for analysing the information flows between network members. In addition to mapping the current information flows, it can also be used in communicating the desirable or optimal state of information flows in the network. The process of conducting a WINA can be presented in the following six steps:

1. Identifying the workflow to be analysed, as well as targets for the development of information management in the workflow.

2. Identifying the various actors as well as their roles in the network. Depending on the development targets set for the analysis, the actors can be e.g. individual people, functional teams, or even companies.

3. Identifying the current state of situational awareness and information flows between the actors in the workflow, as well as documenting the various aspects of information supply (time, content, communication, and context) for each flow.

4. Identifying the information needs of the actors in the workflow and assessing whether the needs are fulfilled and if not, why.

5. Visualizing the results to enhance dissemination and exploitation in the network. Visualizations can be done based on e.g. organization charts, process charts, or as one dimension of a VNA if the company has one in place.

6. Concluding the analysis with concrete suggestions for improving information management and situational awareness in the workflow.

The six steps listed above are demonstrated in more detail in the case study presented in the next section of the paper.

\section{Case study}

A case study from the aviation industry is used to demonstrate the use and benefits of WINA in complex industrial data management contexts. The aviation industry provides a 
fruitful context for the case study because it is strictly regulated and modern aircrafts are very complex technical systems. The case study is a suitable method for the research because the aim is to deepen the understanding of a relatively novel topic, and a case study enables the research of a phenomenon in detail by exploring and giving a rich description of the issue (Eisenhardt, 1989). The ever increasing amount of information and system complexity create additional challenges for many aircraft operation support functions, including the Maintenance, Repair and Overhaul (MRO) of the aircraft fleet.

In step 1 of WINA, the workflow to be analysed is identified and the targets for development are set. This case study has been conducted on an aircraft maintenance organization of a European airline that carries both passengers and cargo. The main objective of the maintenance organization is to perform high quality maintenance, both scheduled and unscheduled, for the airline's Airbus fleet to keep it airworthy and reliable. The target set for the case was to improve aircraft maintenance production through ensuring that essential information flows properly from one actor to another in the network. Maintenance optimization is one of the key tasks in reducing operating costs (Siddique et al., 2018).

In the case study, the information flows of the networked aircraft maintenance organization were analysed. In this case study, the maintenance organization consists of a group of companies and communication with the different departments of the company. These include information flows inside the maintenance organization, but also information flows between the maintenance organization and the other business functions of the airline which produce and/or consume the information managed during the aircraft maintenance process. According to step 2 of WINA, the relevant control centres operating for the airline are briefly introduced:

- The controlling responsibility of the maintenance activities is on the Maintenance Control Centre (MCC). MCC uses operational and airworthiness requirements to control the scheduled and unscheduled maintenance of the aircraft.

- $\quad$ MCC is a part of the Operation Control Centre (OCC) functions of the airline. The main objective of OCC is to maintain the planned flight schedule.

- Subprocesses are managed in The Hub Control Centre (HCC). HCC is responsible for the passenger and cargo flows. To ensure good customer experience and smooth operation, HCC needs to know all the tasks planned for the aircraft during its ground stop.

Data was gathered from several sources to achieve a broad understanding of situational awareness in the case organization at managerial and operational level. Two questionnaires were sent to selected groups of the case organization's personnel. The purpose of the first questionnaire was to map the information paths regarding different people involved in the maintenance function. The questionnaire was sent to 13 people via email. The recipients were selected together with the management of aircraft maintenance, and they included maintenance managers, internal customers (from MCC), maintenance planners, maintenance duty managers, supervisors, and maintenance technicians. The response rate of the first questionnaire was $46 \%$. The second questionnaire concentrated on maintenance process information management. The purpose was to map maintenance information flows and situational awareness between the involved business functions. The questionnaire was sent to 13 people, based on the expert judgement of the maintenance managers in the case organization. The respondents included maintenance managers, managers from MCC, a customer duty manager from 
MCC, planning management, maintenance duty managers, a supervisor, and maintenance technicians. The response rate of the second questionnaire was $70 \%$.

The survey instruments of both questionnaires can be seen in the appendixes of the paper. The survey data was complemented by conducting researcher observations targeted at specific maintenance-related processes in the case organization. A researcher visited the case company, observing how various processes were conducted to get a deeper understanding of the current state of information management in the organization.

Following steps 3 and 4 of WINA, the current state and the information needs in the workflow were analysed and documented. Applying step 5 of the method, the results are visualized in Figure 2 below. The current state of information flows and situational awareness in the workflow are discussed after the figure.

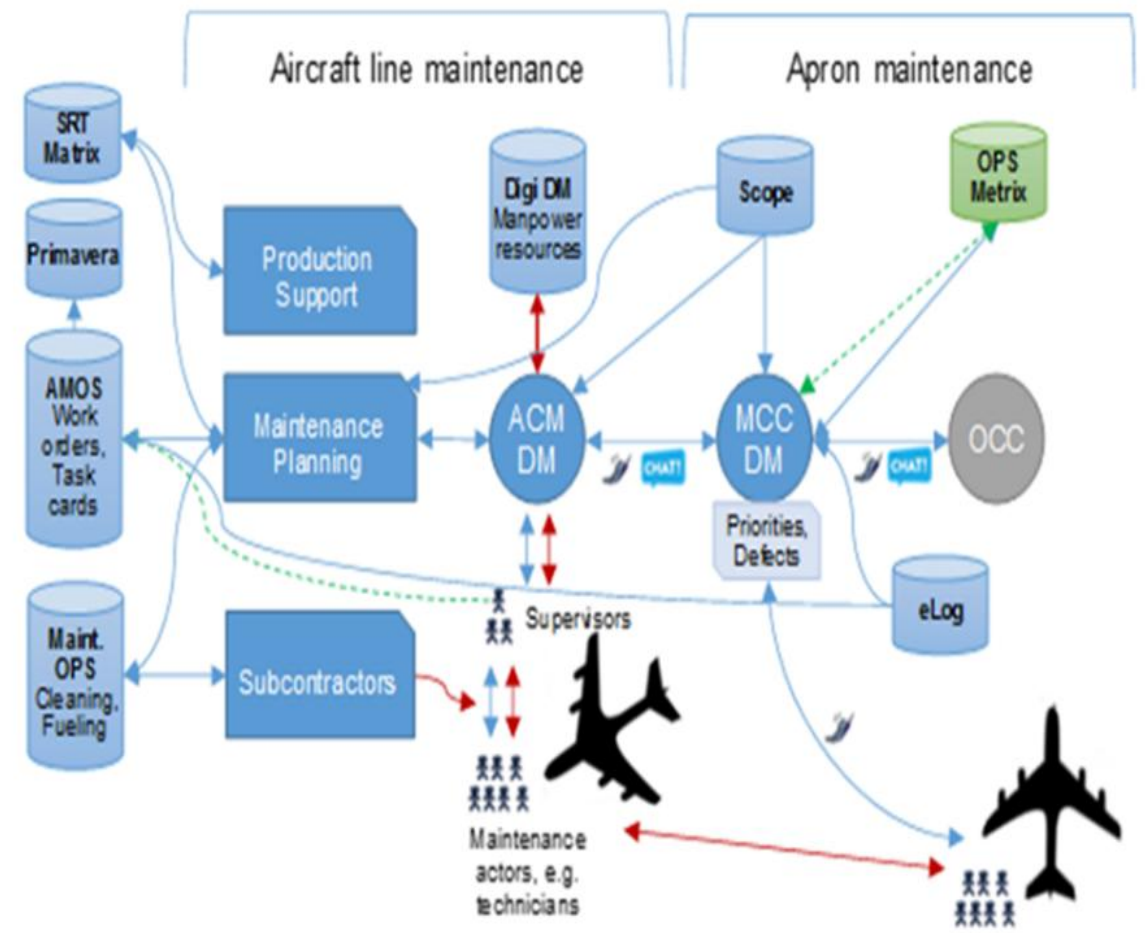

Figure 2. A snapshot of the current information flows in the maintenance work process (ACM DM means Aircraft Maintenance Duty Manager, MCC DM means Maintenance Control Duty Manager, and OCC means Operational Control Center).

The blue arrows in Figure 2 depict defined information, communicated through defined channels and tools. This information is documented in various databases, and is readily available in the value network. These information flows include many of the established databases and software used by the network, e.g. SRT Matrix (a material management software), Primavera (shows the use of maintenance resources compared with the available capacity), AMOS (aircraft maintenance and repair management software), Maint OPS (for ordering subcontracted services), Scope (provides details of each aircraft's flight and maintenance plans) and eLog (an electronic flight logbook where the flight crew reports the found defects). These software support the aircraft 
maintenance duty manager, the maintenance control duty manager, maintenance planning, and production support. Production support includes e.g. spare parts and special tools. It should be noted that some of the defined information flows include information only communicated through e.g. phone calls or radio phones, which creates additional delays to the process and increases the risk of losing some of the information.

The green dashed arrows depict imperfectly defined information content and time. For instance, the maintenance supervisors enter information about completed and open maintenance tasks into the AMOS database, but they often do this at the end of the maintenance technicians' work shift, after collecting the information on paper forms. Information is not received in real time, and that kind of information collection creates an extra stage on work processes, and it can make information quality worse because there are no instructions to enter information into the database. OPS Metrix, on the other hand, is a new software which was not yet fully implemented in the organization and thus included some issues related to information flows. At the moment, there are no clear rules on the time, content, and responsibilities of uploading data to the system.

Finally, the red arrows depict information flows with unspecified information channels or communication tools, which are highly dependent on the actions of individual maintenance experts. There are issues with e.g. how the maintenance technicians report their work and the identified defects to their supervisors, the aircraft maintenance duty manager, and the other technicians in the maintenance organization. Phone calls, radio phones and paper forms are used frequently, making it very challenging to maintain clear situational awareness of the maintenance processes in the organization. Another communication issue was observed with the subcontractors, who get their maintenance task information from the Maint OPS data system and enter the aircraft when allocated by the maintenance organization. After the subcontractors have finished their tasks, the conducted work is documented in the data system. However, the scheduling should be more proactive, so that the aircraft maintenance duty manager would know in advance the planned schedule of all subcontractors. The third issue is related to Digi DM, a planning software used by the aircraft maintenance duty manager to allocate manpower resources between aircraft line maintenance (hangar maintenance) and apron maintenance. The apron is the area where the aircrafts are parked, unloaded, loaded, serviced and boarded. Because apron maintenance (and maintenance control centre) operates closer to the customer interface, it has a higher priority to using personnel resources on a daily basis. However, the current and future need for personnel resources is not always extensively communicated to the aircraft line maintenance.

In general, it can be concluded that the maintenance network uses various systems and databases which operate with different data and parameters. Identifying the current weaknesses in information flows and documenting them was seen valuable for information sharing and development purposes in the organization. Current situational awareness is highly dependent on the manual information sharing routines of individuals. The process is working, due to organizational experience, but it creates extra load for the actors and additional delays to the information flows, and could thus be improved by optimizing the performance of the workflow. This is supported by the two surveys sent to the selected personnel of the maintenance network: $78 \%$ of the respondents thought they received too little information to support their work in maintenance execution, and $88 \%$ completely or partially disagreed when asked whether the progress of maintenance 
execution can be followed in real time. However, it is interesting that $89 \%$ of the same personnel either completely agreed or tended to agree when asked if they knew what information is essential to pass on in the organization to enhance maintenance execution. The authors see two probable explanations for this inconsistency. The first one is that despite acknowledging the situation, the important information is not shared in the maintenance network or it is shared too slowly. The second explanation is that the maintenance personnel thinks they understand their own role in the information management process of the whole network, but that in reality they do not know what information is needed by the other actors. A summary of the information needed before, during and after the maintenance action is presented in Figure 3. Of course, in practice the details of the required information depend on the unit and actor in question.

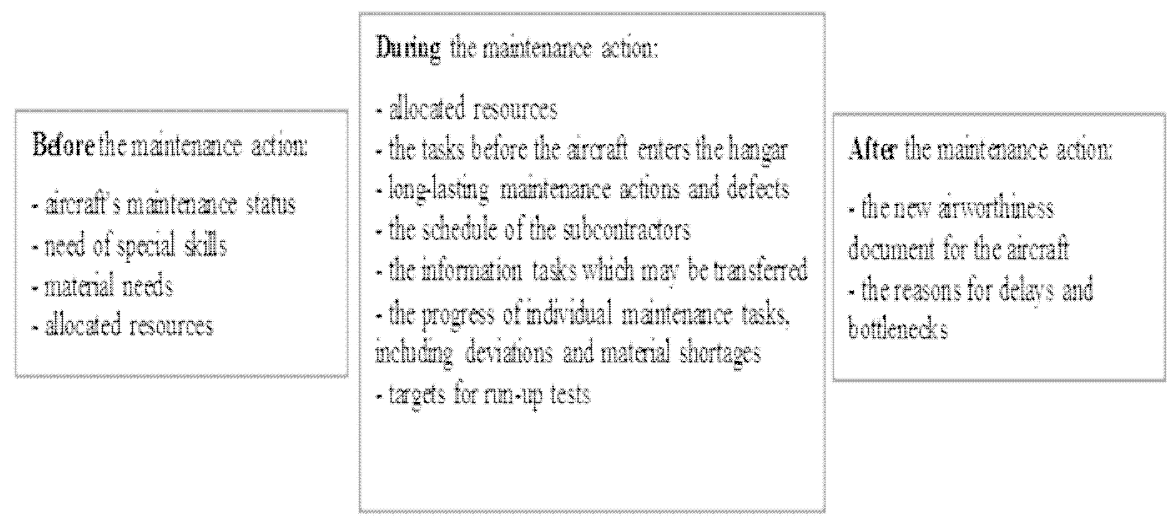

Figure 3. The information needs in the different phases of aircraft maintenance.

According to step 6 of WINA, we conclude the case study by suggesting actions to improve situational awareness in the aircraft maintenance workflow. Firstly, the context awareness of information sharing should be improved to ensure that the personnel knows their roles and importance in the information management process. One solution to this could be to implement WINA on the level of individual maintenance employees, so that the information flows between individual people would be analysed. Secondly, all information management should operate with electronic processes and signatures to avoid excessive delays and to enable real-time situational awareness and proactive management. To optimize performance, all the major stakeholders should be able to follow the maintenance processes in real time. Thirdly, the network could decrease the amount of databases and systems they use for their information management to avoid information deviation. This would of course require careful investment planning and appraisal.

\section{Conclusions}

Following the recent technological development and the vast amount of data available, the information technology landscapes during e.g. the lifecycles of individual products are complex and fragmented (see El Kadiri et al., 2016). The theoretical 
contribution of the paper includes introducing the Workflow Information Network Analysis (WINA), an analytical, managerial method for mapping fragmented information in complex systems. The method is built on the applicable principles of product lifecycle management, information management, and value network analysis. We presented a sixstep process for applying WINA in workflows with fragmented information. The validity of the process has been demonstrated with a case study from the aviation industry. The theoretical contribution of the paper also includes discussing the importance of situational awareness in the context of information management. Some previous research in the area exists, often related to ensuring the safety of critical industrial processes (see e.g. Nazir et al., 2014; Stanton et al., 2001), but most of the earlier discussion on situational awareness has been directed at military contexts. In industrial environments, where real-time information in decision-making is targeted, it would be important to acknowledge the lessons learnt in the military applications.

Regarding managerial contribution, WINA provides industrial decision-makers a novel approach to managing fragmented information flows at multi-actor organizations. With WINA, both the current and the optimal state of information flows between business network members can be analysed in a visual way by using charts. The case study presented in the paper showed that the method supports industrial organizations in identifying discontinuities, bottlenecks, benchmarks etc. in workflow information flows. In practice, improved situational awareness would enable faster information flows, a higher quality of information, reduced risks and improved safety, as well as better support for the decision-makers of the workflows. The operations and maintenance of the product fleet could then be better optimized, and significant monetary and non-monetary benefits could be achieved. WINA is a managerial method, and it supports organizations in developing novel practices, tools or systems to improve information flow management in their business operations. To maximize the impact of the method, WINA should be applied in a centralized way by the management of organizations. The development suggestions, bottlenecks and benchmarks provided by the analysis should then be implemented and adopted versatilely in the foundations of e.g. customer and supplier communications by the marketing and sales department, and in the IT system architecture by the IT department. The value of WINA has been demonstrated in industrial maintenance contexts, but it can be assumed that the method would also work in several other contexts with fragmented information, e.g. in the management of industrial supply and demand chains, or in large projects with extensive consortiums.

Two main limitations can be identified for the paper. The first one is that, in practice, mapping the information flows of a specific workflow is often a time-consuming task which requires a lot of resources from industrial decision-makers. Thus, future research should support WINA through formulating systematic tools and detailed processes to simplify the implementation of the method. Also, the importance of incentives and/or sanctions should be noted: it is not enough for organizations to be aware of the insufficient information flows in the business network. The insufficiencies and development needs must also be integrated into the incentive systems, the real-time IT systems, and organizational structures. In many military contexts, situational awareness can be ensured through authority and chain of command. In industrial business contexts. on the other hand. the motivation of individuals must be managed somewhat differently. Optimizing the motivation of the personnel provides an interesting topic for further research. 
The other limitation is that the paper tests the method with just one case. To rigorously validate the method, future research should test WINA with cases from several different industries. This would help researchers in identifying the strengths of the method in a variety of contexts, as well as in recognizing the special requirements set by a number of operating environments. Further research should also address quantitatively measuring and justifying the benefits of WINA. It would be important for organizations to be able to assess the monetary and non-monetary benefits of improved situational awareness in relation to the additional costs caused by the analysis.

\section{References}

Allee, V. (2008) 'Value network analysis and value conversion of tangible and intangible assets', Journal of Intellectual Capital, 9, 5-24.

Baglee, D., Marttonen, S., \& Galar, D. (2015) 'The need for Big Data collection and analyses to support the development of an advanced maintenance strategy',. In the proceedings of the 11th International Conference on Data Mining, Las Vegas, July 27-30, pp. 3-9.

Barlow, A., \& Li, F. (2005) 'Online value network linkages: integration, information sharing and flexibility', Electronic Commerce Research and Applications, 4, 100112.

Becker, J., Kugeler, M., \& Rosemann, M. (Eds.) (2011) "Process Management, A guide for the design of business processes', Springer Science \& Business Media.

Caglio, A., \& Ditillo, A. (2012) 'Opening the black box of management accounting information exchanges in buyer-supplier relationships', Management Accounting Research, 23, 61-78.

Calais, J.F.L.G., Azevedo, S.G., Matias, J.C.D.O. and Catalão, J.P.D.S. (2017) 'Management and operations maintenance for a water treatment and supply company', Int. J. of Industrial and Systems Engineering, 25(3), pp. 360-382.

Camba, J.D., Contero, M., Company, P., \& Pérez, D. (2017) 'On the integration of model-based feature information in Product Lifecycle Management systems', International Journal of Information Management, 37, 611-621.

Candell, O., Karim, R., \& Söderholm, P. (2009) 'eMaintenance - information logistics for maintenance support', Robotics and Computer-Integrated Manufacturing, 25, 937944.

Christian, T. (2015) 'PLM formulations for chemicals' http://www.cambashi.com/plmchemicals-process-manufacturing Accessed 12.11.15.

Citroen, C.L. (2011) 'The role of information in strategic decision-making', International Journal of Information Management, 31, 493-501.

Davenport, T.H., \& Prusac, L. (2000) 'Working knowledge: how organizations manage what they know', Boston: Harvard Business School Press.

Eisenhardt, K. M. (1989) 'Building theories from case study research', Academy of Management Review, 14, 532-551.

El Kadiri, S., Grabot, B., Thoben, K.-D., Hribernik, K., Emmanouilidis, C., von Cieminski, G., \& Kiritsis, D. (2016) 'Current trends on ICT technologies for enterprise information systems', Computers in Industry, 79, 14-33. 
Endsley, M. R. (1988) 'Design and evaluation for situation awareness enhancement', In the proceedings of the Human Factors Society 32nd Annual Meeting, Santa Monica, CA: Human Factors Society, pp. 97-101.

Endsley, M. R. (1995) 'A taxonomy of situation awareness errors', Human factors in aviation operations, 3, 287-292.

Ferreirab, F., Fariaa, J., Azevedoa, A., \& Marquesa, A.L. (2017) 'Product lifecycle management in knowledge intensive collaborative environments: an application to automotive industry', International Journal of Information Management, 37, 14741487.

Grieves, M. (2008) 'Product specification management (PSM): enabling manufacturing quality', White paper. https://www.qmc.com/Portals/0/pdf_resources/psm.pdf Accessed 17.07.17.

Harrald, J., \& Jefferson, T. (2007) 'Shared situational awareness in emergency management mitigation and response', In System Sciences, 2007. HICSS 2007. 40th Annual Hawaii International Conference on System Sciences, IEEE.

Hong-Bae, J., \& Kiritsis, D. (2012) 'Several aspects of information flows in PLM', In L. Rivest, A. Bouras, \& B. Louhichi (Eds.), Product lifecycle management. Towards knowledge-rich enterprises (pp. 14-24). Heidelberg: Springer.

Huang, K., Kong, X. and Liu, L. (2018) 'Analytical model of information system development productivity in adaptive and perfective maintenance phases', Int. J. Industrial and Systems Engineering, Vol. 29, No. 3, pp. 338-351.

Karim, R., Söderholm, P., \& Candell, O. (2009) 'Development of ICT-based maintenance support services', Journal of Quality in Maintenance Engineering, 15, 127-150.

Karimi, S.S., Karbasian, M. and Tavakkoli-Moghaddam, R. (2018) 'Availability optimisation of multi-state series-parallel systems with human failures', Int. J. of Industrial and Systems Engineering, 29(2), pp. 127-143.

Kinnunen, S.-K., Marttonen-Arola, S., Ylä-Kujala, A., Kärri, T., Ahonen, T., Valkokari, P., \& Baglee, D. (2016) 'Decision making situations define data requirements in fleet asset management', In the proceedings of the 10th World Congress in Engineering Asset Management (WCEAM 2015), Lecture Notes in Mechanical Engineering (21954356), Springer, pp. 357-364.

La Rocca, A., \& Snehota, I. (2014) 'Value creation and organizational practices at firm boundaries', Management Decision, 52, 2-17.

Meira, J., Kartalis, N., Tsamenyi, M., \& Cullen, J. (2010) 'Management controls and inter-firm relationships: a review', Journal of Accounting \& Organizational Change, 6, 149-169.

Meissen, U., Pfennigschmidt, S., Voisard, A., \& Wahnfried, T. (2005) 'Context- and situation-awareness in information logistics', In W. Lindner, M. Mesiti, C. Türker, Y. Tzitzikas, \& A.I. Vakali (Eds.), Current trends in database technology - EDBT 2004 Workshops. (pp. 335-344). Heidelberg: Springer.

Merrill, J., Bakken, S., Rockoff, M., Gebbie, K., \& Carley, K.M. (2007) 'Description of a method to support public health information management: organizational network analysis', Journal of Biomedical Informatics, 40, 422-428.

Moumen, M. and Aoufir, H.E. (2018) 'Use and relevance of quality, safety and environment management tools and techniques: an empirical investigation, case of Moroccan companies', Int. J. of Industrial and Systems Engineering, 29(2), pp.144162. 
Nazir, S., Sorensen, L.J., Øvergård, K.I., \& Manca, D. (2014) 'How distributed situation awareness influences process safety', Chemical Engineering Transactions, 36, 409414.

Olaisen, J., \& Revang, O. (2017) 'Working smarter and greener: collaborative knowledge sharing in virtual global project teams', International Journal of Information Management, 37, 1441-1448.

Pareschi, R., \& Fontana, F.A. (2016) 'Information-driven network analysis: evolving the “complex networks' paradigm', Mind \& Society: Cognitive Studies in Economics and Social Sciences, 15, 155-167.

Paryzad, B, Najafi, E., Kazemipoor, H. and Pour, N.S. (2018) 'The new ranking method of the decision making units in DEA: with an approach to modifying the cross efficiency method', Int. J. Industrial and Systems Engineering, Vol. 30, No. 3, pp. 387-400.

PLM (2015) 'Product Lifecycle Management (PLM)'. http://www.product-lifecyclemanagement.com/ Accessed 12.11.15.

Ranasinghe, D.C., Harrison, M., Främling, K., \& McFarlane, D. (2011) 'Enabling through life product-instance management: solutions and challenges', Journal of Network and Computer Applications, 34, 1015-1031.

Samant, S., Mittal, V.K. and Prakash, R. (2018). 'Resource optimisation for an automobile chassis manufacturer through value stream mapping enhanced with simulation technique and constraint programming', Int. J. Industrial and Systems Engineering, Vol. 28, No. 3, pp. 379-401.

Shalij, P., Devadasan, S., \& Prabhushankar, G. (2009) 'Design of ISO 9001:2000 based supply chain quality management systems', International Journal of Process Management and Benchmarking, 3, 1-23.

Siddique, P.J., Luong, H.T. and Shafiq, M. (2018) 'An optimal joint maintenance and spare parts inventory model', Int. J. Industrial and Systems Engineering, Vol. 29, No. 2, pp. 177-192.

Silventoinen, A., Denger, A., Lampela, H., \& Papinniemi, J. (2014) 'Challenges of information reuse in customer-oriented engineering networks', International Journal of Information Management, 34, 720-732.

Siponen, M., Haapasalo, H. and Harkonen, J. (2019) 'Maintenance, repair, and operations inventory reduction and operational development', Int. J. Industrial and Systems Engineering, Vol. 32, No. 1, pp.1-31.

Soto-Acosta, P., Placer-Maruri, E., \& Perez-Gonzalez, D. (2016) 'A case analysis of a product lifecycle information management framework for SMEs', International Journal of Information Management, 36, 240-244.

Stanton, N.A., Chambers, P.R.G., \& Piggott, J. (2001) 'Situational awareness and safety', Safety Science, 39, 189-204.

Stark, J. (2015) 'Product Lifecycle Management' (Volume 1). 21st Century Paradigm for Product Realisation. (3rd ed.). Cham: Springer, (Chapter 5).

Symon, G. (2000) 'Information and communication technologies and the network organization: a critical analysis', Journal of Occupational and Organisational Psychology, 73, 389-414.

Takata, S., Kimura, F., van Houten, F.J.A.M., Westkämper, E., Shpitalni, M., Ceglarek, D., \& Lee, J. (2004) 'Maintenance: changing role in life cycle management', CIRP Annals - Manufacturing Technology, 53, 643-655. 
Tesone, D.R., \& Goodall, J.R. (2007) 'Balancing interactive data management of massive data with situational awareness through smart aggregation', In the proceedings of the IEEE Symposium on Visual Analytics Science and Technology, Sacramento, CA, October 30 - November 1, pp. 67-74.

Thatcher, A., Vasconcelos, A.C., \& Ellis, D. (2015) 'An investigation into the impact of information behaviour on information failure: fhe Fukushima Daiichi nuclear power disaster', International Journal of Information Management, 35, 57-63.

Thom, W. (2009) 'People, Process, and Performance Management in Project Management', https://pmhut.com/people-process-and-performance-management-inproject-management Accessed 14.08.17.

Tsarouhas, P. (2019) 'Evaluation of reliability, availability and maintainability of a milk production line', Int. J. Industrial and Systems Engineering, Vol. 31, No. 3, pp. 324342.

United States Department of Homeland Security (2004) 'Team coordination training, student guide' https://www.uscg.mil/auxiliary/training/tct/ Accessed 05.03.17.

van Houten, G. (2000) “ISO 9001:2000: a standard for all industries', Information Management Journal, 34, 28-37.

Vargo, S.L., \& Lusch, R.F. (2008) 'Service-dominant logic: continuing the evolution', Journal of the Academy of Marketing Science, 36, 1-10.

Veeramanikandan, R., Nithish, S., Sivaraj, G. and Vinodh, S. (2017) 'Life cycle assessment of an aircraft component: a case study', Int. J. Industrial and Systems Engineering, Vol. 27, No. 4, pp. 485-499. 